\title{
LIBROS RECIBIDOS
}



ACTAS DE LAS XI JORNADAS DE LA ASOCIACIÓN DE LETRADOS DEL TRIBUNAL CONSTITUCIONAL: Extranjería e inmigración, Madrid: Tribunal Constitucional. CEPC, 2004, 427 pp.

Una vez más la Asociación de Letrados del Tribunal Constitucional ha elegido como tema de sus Jornadas anuales uno candente y dotado del máximo interés, como lo es el estudio del impacto de la inmigración extranjera hoy en España, desde la perspectiva de nuestro sistema jurídico político. La primera parte de esta obra recoge tres estudios, el primero de Ruth Rubio Marín sobre "La inclusión del inmigrante: un reto para las democracias constitucionales", el siguiente de Luis Pomed Sánchez versa sobre "Algunas consideraciones sobre la situación actual del Derecho de inmigración en España" y el tercero de Francisco Caamaño Domínguez acerca "De la igualdad como legalidad a la igualdad como dignidad. Reflexiones, en clave constitucional, sobre una sociedad decenten. La segunda parte recopila cinco crónicas de jurisprudencia constitucional, que abordan aspectos más o menos puntuales de la temática objeto de estas XI Jornadas que han mantenido el nivel elevado de las anteriores.

Alguacil GonZÁlez-Aurioles, Jorge, La elaboración del Tratado por el que se establece una Constitución para Europa, Madrid: BOE. CEPC, 2004, 395 pp.

El presente volumen contiene una serie de documentos de la Convención sobre el Futuro de Europa y otros surgidos con ocasión de los debates. Tales documentos condensan los conflictos surgidos a lo largo del proceso de integración. Fruto de ellos es el proyecto de Tratado que aprobó la Convención y que tras las modificaciones realizadas en las Conferencias Intergubernamentales de Roma y Dublín se ha convertido en el actual Tratado por el que se establece una Constitución para Europa. La introducción describe y valora este proceso. Los documentos están ordenados en torno a una serie de temas: la naturaleza de la Unión, los derechos fundamentales, la distribución de competencias, la Europa social, las instituciones, las fuentes del Derecho y los parlamentos nacionales. Los sucesivos referenda sobre el Tratado convocados por los Estados miembros actualizaron el debate y la actual situación en que se encuentra la Unión Europea parece imponer una reflexión profunda sobre el proceso de construcción europeo que no puede prescindir de la experiencia acumulada. 
Alvarez Conde, Enrique, El derecho de partidos, Madrid: Colex, 2005, 406 pp.

Esta obra surge, tal y como explica el autor en la presentación de la misma, como consecuencia de la inquietud por dar una respuesta adecuada a la cuestión "qué partidos en una democracia", inquietud nacida a partir de la creación por toda Europa de formaciones políticas de escasas convicciones democráticas, y reforzada con la aprobación de la Ley Orgánica de Partidos Políticos y el proceso de ilegalización de Batasuna. Estas cuestiones, que son objeto todas ellas de detallado análisis en el libro, llevan al autor a revisar las materias que integran lo que se ha dado en llamar "el derecho de partidos", es decir, la propia concepción del derecho de partidos (Cap. I), la posición constitucional de los partidos políticos (Cap. II), el régimen jurídico de los mismos (Cap. III), partidos políticos y derecho electoral (Cap. IV), partidos políticos y derecho parlamentario (Cap. V.), y, finalmente, la financiación de los partidos (Cap. VI). A lo largo del análisis de todas estas materias, el autor ha tratado de mostrar el grado de elaboración de esta disciplina jurídica, poniendo especial énfasis en resaltar las incoherencias, lagunas y deficiencias existentes que exigen, a su juicio, una reforma profunda y urgente de la actual normativa. En las últimas líneas de la introducción al libro, el prof. Alvarez Conde agradece y deja constancia de la colaboración del prof. Alexandre H. Catalá Bas, que, además, se ha ocupado de la redacción de algunos de los epígrafes de la obra.

Aragón Reyes, Manuel; Gómez Montoro, Ángel (coords.), El Gobierno. Problemas constitucionales, Madrid: CEPC, 2005, 650 pp.

Obra colectiva, resultado de un Proyecto de Investigación en el que han colaborado diferentes profesores de Derecho Constitucional de las Universidades de Valladolid y Autónoma de Madrid, en el que se abordan las grandes rúbricas del tema objeto de estudio: la forma de Gobierno, el Gobierno como órgano constitucional, la dirección por el Gobierno de la Administración civil y militar, la intervención del Gobierno en la función presupuestaria, el control parlamentario del Gobierno, el control de los Decretos Legislativos, el control jurisdiccional del Gobierno, el Gobierno en funciones, los Gobiernos de las Comunidades Autónomas y Gobierno y Unión Europea. Dos son los elementos que sirven de hilo conductor a los distintos trabajos: la especial atención a las necesidades de delimitación de las competencias gubernamentales y, en consecuencia, a los controles de las mismas.

Brage Camazano, Joaquín, Los limites a los derechos fundamentales, Dykinson, Madrid, 2004, 445 pp.

La presente investigación, fruto de la tesis realizada por el autor, analiza el método que debe seguirse para precisar el alcance de los derechos fundamentales; la vaguedad e indeterminación de las disposiciones constitucionales 
que los reconocen hace que la tarea no sea en absoluto fácil. La investigación se apoya sobre los ricos y valiosos materiales que proporciona el Derecho alemán, que es objeto de un análisis profundo y exhaustivo. El alcance de los derechos fundamentales debe ser determinado en cada caso a través de un método escalonado: delimitando en primer lugar el llamado ámbito de protección del derecho fundamental, precisando en segundo lugar si la actuación u omisión enjuiciada - que puede provenir de un poder público o incluso de un particular-constituye una intervención en dicho ámbito, es decir, si recorta las posibilidades de actuación o protección reconocidas en principio por el derecho fundamental; en último extremo se ha de verificar si la intervención cumple los requisitos formales y materiales establecidos para ser conformes con la Constitución. El autor fundamenta las razones que explican la conveniencia de seguir este método escalonado, lo que le sirve para abordar diversos aspectos de la teoría general de los derechos fundamentales: la relevancia de la cláusula del contenido esencial, la eficacia directa entre particulares de los derechos fundamentales, el control judicial de la discrecionalidad de que gozan las autoridades públicas, en especial el legislador, para restringirlos, la concurrencia de varios de estos derechos frente a una intervención, los conflictos entre ellos, la protección de los mismos frente a las injerencias procedentes del extranjero.

Castellà Andreu, Josep M.a : La función constitucional del Estatuto de Autonomía de Cataluña, Barcelona: Institut d’Estudis Autonòmics, 2004, 239 pp.

Esta monografía parte de centrar la naturaleza jurídica de los Estatutos elaborados conforme al art. 151.2 CE en su condición de norma pactada - de rango diferente al de una Ley orgánica-, que, según se sostiene, no concurre en los restantes estatutos y que, conforme se defiende, afecta a su contenido a su reforma y a su posición en el ordenamiento jurídico. Las últimas conclusiones de este trabajo se centran en lo que se da en llamar las funciones constitucionales del Estatuto de Autonomía de Cataluña como un posible criterio de identificación del Estado autonómico, más que polémicas dada su dudosa compatibilidad con nuestra Constitución vigente. Obra interesante para conocer los criterios en la materia de sectores significativos del nacionalismo catalán a la hora de intentarse abordar la reforma de dicho Estatuto.

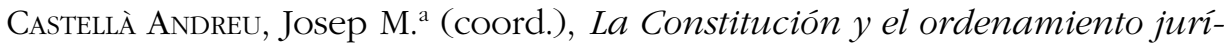
dico/La Constitució i l'ordenament jurídic, Barcelona: Facultad de Derecho de la Universidad de Barcelona/Atelier, 2005, 519 pp.

La Facultad de Derecho de la Universidad de Barcelona conmemoró el XXV aniversario de la aprobación de la Constitución con la celebración de un ciclo de conferencias en que se valoraba la repercusión que ha tenido la 
Constitución de 1978 en las diferentes ramas del Derecho: el libro recoge las ponencias de este seminario, a cargo de docentes de las diferentes disciplinas jurídicas en dicha Facultad. Los autores reflexionan sobre la evolución de sus respectivas materias en los años transcurridos desde 1978 y sobre los retos que hay que afrontar cara al futuro; así, se analiza cómo las normas constitucionales y la jurisprudencia del Tribunal Constitucional han afectado a la normativa precedente, alterando aspectos claves del derecho positivo español, y han inspirado nuevas regulaciones en amplios sectores del ordenamiento jurídico; igualmente se contextualiza la Constitución de 1978 en la historia del Derecho constitucional español y en las corrientes filosóficas y políticas del momento en que se aprobó; los autores, en fin, tampoco pierden de vista el debate político y jurídico más reciente sobre la conveniencia o no de afrontar su reforma.

Cruz Villalón, Pedro, La Constitución inédita. Estudios ante la constitucionalización de Europa, Madrid: Trotta, 2004, 157 pp.

Los diversos artículos recogidos en este libro perfilan sobre todo un determinado método para la construcción dogmática del Derecho constitucional europeo, y lo aplican luego a aspectos concretos del mismo (jurisdicción constitucional, autonomías territoriales, carta de derechos ...): porque «la práctica de la Constitución reclama la teoría de la Constitución.. En efecto, la creciente europeización de nuestro espacio constitucional, la consolidación de un "bloque formado por la Constitución de la Unión y las de los Estados" como "bloque europeo de la constitucionalidad", requiere una dogmática adecuada, que haga justicia a "los viejos principios que han hecho posibles órdenes constitucionales como el español de 1978", pero que también dé cobijo a la Unión bajo el "acervo constitucional generado por los Estados". A juicio del autor, "estamos ante una constitucionalidad derivada", el centro de gravedad "es y seguirá siendo todavía el constitucionalismo estatal", lo que en cierta medida produce una irreductible asimetría constitucional en el seno de la Unión: de garantizarlo se ocupa el mandato de preservación de las identidades nacionales, que se suelen concretar en rasgos constitucionales. Pero, simultáneamente, "la calidad constitucional de cada Estado miembro resulta también afectada por la calidad constitucional de cada uno de los restantes Estados miembros" y, naturalmente, "condicionada por la calidad de la propia civitas europea". De este modo, "la pertenencia a la Unión resulta constitucionalmente relevante"; sólo como ejemplo, dado que "los poderes del Estado adquieren una segunda funcionalidad ... como co-actores del Derecho comunitario", la propia Unión llega a condicionar «el desempeño del poder público en el interior de los Estados miembros a fin de promover un interés comunitario" de naturaleza constitucional. Ante la complejidad resultante, Pedro Cruz postula un principio de "concertación constitucional" capaz de generar coherencia a partir de mecanismos de referencia recíproca entre las disposiciones constitucionales de los 
diferentes niveles. Este modo de aproximación, por supuesto, no queda en entredicho porque el proceso de ratificación del Tratado constitucional europeo haya quedado en suspenso; el "espacio constitucional europeo" depende sólo en su modo, no en su existencia, de la adopción en Europa de un texto normativo que incorpore en su rúbrica el término Constitución; y, de hecho, el autor utilizaba precisamente su afilado método para criticar tanto el proyecto de Tratado (en no pocos extremos) como el proceso previsto para su ratificación en España.

Fernández Sarasola, Ignacio, Proyectos constitucionales en España (17861824), Madrid: Clásicos del Pensamiento Político y Constitucional Español, CEPC, 2004, 797 pp.

Se recogen en esta obra los proyectos constitucionales, entendidos como «teorización reflejada en un texto articulado, orientado a servir como Constitución nacional, o bien como bases constitucionales para un documento más detallado", elaborados en España durante el período que media entre 1786 y 1824 . Los proyectos, que no se presentan de forma cronológica, sino encuadrados conforme los modelos liberal, afrancesado y reformista en orden a su mejor comprensión, vienen precedidos de estudios específicos en donde se sintetizan su elaboración y caracteres esenciales. A ello se añade un interesante y extenso estudio preliminar a todos ellos que permite obtener una visión de conjunto del pensamiento político constitucional durante este período. Se incorporan en la obra igualmente dos apéndices en donde se recogen, siempre dentro del período objeto de referencia, "programas constitucionales" (textos que contendrían un programa básico no articulado o articulado de forma imperfecta, a fin de servir de guía para una elaboración normativa más detallada) así como el índice de algunas obras doctrinales que habrían sido elaboradas conforme la estructura de un texto constitucional.

Gavara de Cara, Juan Carlos, Contenido y función del término de comparación en la aplicación del principio de igualdad, Navarra: Aranzadi, 2005, 226 pp.

La investigación se articula en torno a la necesidad de establecer las razones por las cuales en unas ocasiones un Tribunal Constitucional permite articular un término de comparación y otras no, a pesar de enfrentarse a un mismo supuesto factual de similares, equiparables y homogéneas características. Como punto de partida se ha analizado el significado de la necesidad de comparación como elemento determinante de la aplicación del principio de igualdad. Otro objetivo de la investigación ha sido la determinación de la ubicación del término de comparación en la estructura del principio de igualdad en la ley. Se ha 
optado así por un análisis descriptivo del juicio de igualdad estructurado en torno a tres puntos: la determinación de la diferenciación y su relevancia constitucional, la justificación de la diferenciación y, por último, la corrección constitucional de la diferenciación introducida. En la investigación se defiende que dado que el término de comparación presenta un grado elevado de complejidad, se considera el elemento factual del supuesto de hecho tan sólo uno de los componentes que lo forman. Los componentes del término de comparación son así, en primer lugar, el elemento factual de comparación, es decir, los hechos, situaciones o regímenes jurídicos diferentes. En segundo lugar se debe determinar la fijación de las similitudes y las diferencias del elemento factual. Por último, la finalidad y la perspectiva de la comparación para su aceptación por el Tribunal Constitucional.

Gutiérrez GutiérRez, Ignacio, Dignidad de la persona y derechos fundamentales, Madrid/Barcelona: Marcial Pons, 1995, 239 pp.

Esta obra contribuye a formular una teoría general de los derechos fundamentales no sólo estructural, sino material, y por ello histórica; consecuentemente, no pretende depurar técnicamente la dogmática de los derechos fundamentales, sino explicitar la función efectiva que se les ha ido atribuyendo en el actual Estado constitucional en relación con las posibilidades abiertas en cada caso por el Derecho constitucional positivo. Para ello adopta la perspectiva más amplia y a la vez más sintética posible dentro del ámbito de los derechos fundamentales, la que ofrece el postulado de la dignidad de la persona, y documenta el papel que desempeña en el ordenamiento constitucional español, en particular mediante un análisis exhaustivo y sistemático de la jurisprudencia del Tribunal Constitucional que, en formas y con alcances bien diversos, la ha invocado (capítulo II). Pese a la multitud de sentencias y el énfasis de la doctrina, tal papel resultaría en verdad limitado: la dignidad de la persona, que no incorpora por sí misma un derecho fundamental, tampoco consigue elevar los derechos fundamentales a sistema, ni siquiera permite identificar de modo unívoco el sujeto de los mismos. Tal conclusión se refuerza con tres estudios específicos sobre al titularidad de los derechos fundamentales por parte de los embriones, de las personas jurídicas de Derecho público y de los extranjeros (capítulo III). Esta situación contrasta con la relevancia que atribuye el Derecho constitucional alemán a la dignidad humana, analizada con detalle y atendiendo a las diferentes tendencias doctrinales en el capítulo I. Mas puede ser comprendida a la luz de las transformaciones del Estado constitucional, que parece haber ido sustituyendo la imagen unitaria del hombre y de su dignidad por una serie de garantías estratégicas de intereses objetivos diferenciados (capítulo IV). El libro se cierra con la explicación histórica de esa quiebra de la dignidad en múltiples facetas, a la que el ordenamiento constitucional español parece haberse resignado, renunciando a recomponer un perfil normativo de la imagen del hombre. 
Péces Barba, Gregorio; RAMiro Avilés, Miguel Ángel (Coords.), La Constitución a examen, Madrid: Marcial Pons, 2004, 828 pp.

En este obra, coordinada por uno de los ponentes de nuestro texto constitucional, se recogen las conferencias del seminario 25 Aniversario de la Constitución española, 1978-2003 celebrado en diciembre de 2003 en la Universidad Carlos III de Madrid. En este seminario especialistas de diferentes disciplinas (Filosofía del Derecho, Derecho Aministrativo, Derecho Civil, Derecho Financiero, Derecho del Trabajo.... y, por supuesto, Derecho Constitucional) expusieron sus planteamientos (preocupaciones, valoraciones y propuestas de mejora) respecto de nuestro norma fundamental. Resultando imposible referir la totalidad de las ponencias presentadas, reseñamos únicamente algunas de ellas ejemplificativamente: "Cultura jurídico-política en la Constitución de 1978", de Roberto L. Blanco Valdés; "La cultura constitucional", de José Luis Cascajo Castro; «Separación de poderes y democracia en la Constitución", de Francisco Rubio Llorente; "La garantía de la Constitución", de Luis López Guerra; «Le mort saisit le vie. Los derechos históricos: novación y continuidad", de Javier Corcuera Atienza; "Los hechos diferenciales en la Constitución", de Frances de Carreras; o "La reforma de la Constitución veinticinco años después (la apertura del melón)", de Pablo Pérez Tremps.

Ruz Robledo, Agustín: El Derecho fundamental a la legalidad punitiva, Valencia: Tirant Lo Blanch, 2003, 398 pp.

Monografía prologada por el profesor Pérez Royo, que versa sobre el principio de legalidad penal, que no por estar consagrado desde las ya lejanas fechas de la Revolución francesa deja de plantear importantes facetas de interés actual, empezando por nuestra reserva de Ley orgánica.. El autor analiza el alcance actual de los requisitos de lex previa y lex certa, para terminar con una serie de consideraciones sobre el marco de actuación del derecho fundamental a la legalidad en materias tales como ilícitos privados, cargas procesales, recargos por incumplimientos de los plazos tributarios, actuaciones administrativas que imponen alguna obligación, los supuestos de expropiación-sanción o los casos de revocación de licencias o, en general, de cualquier autorización previa.

Viciano Pastor, Roberto, Constitución y reforma de los Estatutos de Autonomía, Valencia: Tirant lo Blanch, 2005, 213 pp.

La Constitución contiene una escuetas referencias a la reforma de los Estatutos de Autonomía, siendo ante todo estos mismos los que se ocupan de regular el correspondiente proceso, especialmente en su fase inicial; como es sabido, la reforma sólo se culmina tras la aprobación por las Cortes Generales de la correspondiente Ley Orgánica. Este libro estudia las referidas disposiciones 
constitucionales, su génesis y su sentido, y especialmente realiza un exhaustivo análisis comparativo de los trámites (iniciativa, tramitación en los parlamentos regionales, procedimiento en las Cortes Generales, referéndum en su caso, diversos procedimientos especiales) que permiten llevar a cabo tales reformas conforme a la regulación contenida en los diecinueve Estatutos vigentes; el último capítulo se refiere a "las modificaciones no formales de los Estatutos de Autonomía", en particular derivadas de una reforma en otras normas integrantes del llamado bloque de la constitucionalidad (comenzando por la propia Constitución y por los Tratados que, conforme a ella, pueden transferir competencias a organizaciones internacionales). El hecho de que la reforma de los Estatutos de Autonomía sea un asunto de la agenda política inmediata incrementa el interés de una obra que desmenuza sus aspectos procedimentales; baste recordar que desde esta perspectiva debe abordarse el problema de la mayoría necesaria en una Cámara autonómica para proponer una reforma del Estatuto de Autonomía o la pertinencia de una votación preliminar que permita la toma en consideración de la propuesta procedente de una Asamblea Autonómica por parte del Congreso de los Diputados. 